\title{
PROFIL PROBLEM EMOSI/ PERILAKU PADA REMAJA PELAJAR SMP-SMA DI KOTA SEMARANG
}

\author{
Annastasia Ediati \\ Fakultas Psikologi Univeristas Diponegoro \\ J1. Prof. Soedharto SH Tembalang Semarang \\ ediati@undip.ac.id
}

\begin{abstract}
The aims of this study is to identify the profile of emotional/behavioral problems on adolescents students of junior and senior high school (SMP-SMA) in Semarang, Central Java. The subjects comprised 568 students (grade VII and X; males and females), aged between 13-17 years. Data were collected using the Indonesian translation of the Youth Self Report (YSR). The results of data analysis showed that adolescents in the junior high school/SMP reported emotional/behavioral problems more frequently than the adolescents in the senior high school/SMA $(\mathrm{t}(566)=2.08, \mathrm{p}=.038)$, especially in terms of social relations $(\mathrm{t}(566)=2.92, \mathrm{p}=.004)$, thought problems $(\mathrm{t}(566)=2.47, \mathrm{p}=.014)$, somatic complaints $(\mathrm{t}(566)=2.98, \mathrm{p}=.002)$, rule-breaking behavior $(\mathrm{t}(566)=6.63, \mathrm{p}<.001)$, and externalizing problems $(\mathrm{t}(566)=3,37 ; p=.001)$. Gender differences was found in the adolescents' emotional/behavioral problems. In group of junior high school students (SMP), girls reported more emotional problems than boys $(\mathrm{t}(335)=-3.55 ; p<.001)$, particularly in anxiety/depression $(\mathrm{t}(335)=-6.51$; $p<.001)$; withdrawal $(\mathrm{t}(335)=-4.26 ; p<.001)$, somatic complaints $(\mathrm{t}(335)=-2.86 ; p=.004)$; social problems $(\mathrm{t}(335)=-3.30 ; p=.001)$, attention problems $(\mathrm{t}(335)=-2.39 ; p=.017)$; and internalizing problem $(\mathrm{t}(335)=-$ $5.76 ; p<.001)$. In group of senior high school students (SMA), boys reported more externalizing problems $(\mathrm{t}(229)=2.10 ; p=.037)$ and rule-breaking behavior $(\mathrm{t}(229)=4.44 ; p<.001)$ than girls. In contrasts, girls reported more somatic complaints than boys $(\mathrm{t}(229)=-3.09 ; p=.001)$. Adolescents' emotional/behavioral problems should gained more attention. Preventive as well as curative intervention is needed, particularly intervention that sensitive to gender and age, which also involve significant figures for adolescents (parents, school teachers, and peers).
\end{abstract}

Keywords: emotional problems, behavioral problems, adolescents, high school, gender, Semarang

\begin{abstract}
Abstrak
Penelitian ini bertujuan untuk mengidentifikasi profil problem emosi/perilaku pada remaja pelajar SMP dan SMA di Kota Semarang, Jawa Tengah. Subjek penelitian ini adalah 568 siswa-siswi kelas VII dan kelas X, berusia antara 13-17 tahun, laki-laki maupun perempuan. Data problem emosi dikumpulkan menggunakan Youth Self Report (YSR) edisi Bahasa Indonesia. Hasil analisis data menunjukkan bahwa remaja SMP memiliki lebih banyak problem emosi/perilaku daripada remaja SMA $(t(566)=2,08 ; p=0,038)$, terutama dalam hal bergaul $(t(566)=2,92 ; p=0,004)$; berpikir $(\mathrm{t}(566)=2,47 ; p=0,014)$; keluhan somatik $(\mathrm{t}(566)=2,98 ; p=0,002)$; melanggar aturan $(\mathrm{t}(566)=6,63 ; p<0,001)$; dan externalizing problem $(\mathrm{t}(566)=3,37 ; p=0,001)$. Perbedaan gender tampak pada perbedaan domain problem emosi subjek. Pada kelompok remaja SMP, perempuan pada umumnya memiliki lebih banyak problem emosi daripada laki-laki $(\mathrm{t}(335)=-3,55 ; p<0,001)$, terutama dalam hal kecemasan/depresi $(\mathrm{t}(335)=-6,51 ; p<0,001)$; menarik diri dari pergaulan $(\mathrm{t}(335)=-4,26 ; p<0,001)$, keluhan somatik $(\mathrm{t}(335)=-2,86 ; p=0,004)$; kesulitan bergaul $(\mathrm{t}(335)=-3,30 ; p=0,001)$, memusatkan konsentrasi $(\mathrm{t}(335)=-2,39 ; p=0,017)$; dan internalizing problem $(\mathrm{t}(335)=-5,76 ; p<0,001)$. Sedangkan pada remaja SMA, laki-laki lebih sering mengalami externalizing problem $(\mathrm{t}(229)=2,10 ; p=0,037)$ dan lebih banyak melanggar aturan $(\mathrm{t}(229)=4,44 ; p<0,001)$ daripada perempuan. Sebaliknya, perempuan lebih sering mengalami keluhan fisik karena problem psikologis daripada laki-laki $(\mathrm{t}(229)=-3,09 ; p=0,001)$. Problem emosi remaja perlu mendapatkan perhatian serius dan penanganan segera. Diperlukan intervensi yang bersifat preventif maupun kuratif yang sensitif terhadap gender dan usia serta melibatkan lingkungan terdekat remaja (orangtua, sekolah, dan teman sebaya).
\end{abstract}

Kata kunci: problem emosi, problem perilaku, remaja, SMP, SMA, gender, Semarang

\section{PENDAHULUAN}

Masalah emosi dan perilaku pada anak dan remaja dapat berdampak negatif terhadap tumbuh kembang dan kehidupan seharihari mereka. Gangguan perkembangan kognitif, kesulitan memusatkan perhatian 
yang akhirnya berujung pada kesulitan belajar, memori atau daya ingat yang buruk, atau tingkah laku yang tidak adekuat di dalam lingkungan pergaulan di sekolah, dapat menjadi titik tolak berkembangnya pola perilaku menyimpang dan kriminalitas di masa dewasa (Beesdo dkk, 2007; Donovan \& Spence, 2000; Roza, Hofstra, van der Ende, \& Verhulst, 2003).

Secara empiris, taksonomi problem emosi dapat dibagi menjadi dua dimensi umum, yakni internalizing problem dan externalizing problem (Sourander \& Helstelä, 2005). Externalizing problem dapat dilihat dari munculnya konflik dengan orang lain atau dikarenakan harapan yang tidak tercapai, seperti perilaku agrresif dan perilaku delinkuen. Sedangkan internalizing problem mengindikasikan adanya tekanan di dalam diri individu, seperti depresi, kecemasan, menarik diri dari lingkungan pergaulan, dan keluhan somatik yang dapat berdampak negatif pada harga diri (selfesteem), prestasi belajar, kesehatan, kompetensi sosial, penyesuaian diri individu di masa yang akan datang. Internalizing problem sulit diindetifikasi oleh orang lain karena internalizing problem merupakan persepsi subyektif individu terhadap tekanan/stress di dalam dirinya (Sourander \& Helstelä, 2005).

Achenbach dan Rescorla (2001) mengidentifikasi delapan jenis problem emosi pada anak dan remaja, yakni: 1) kecemasan/depresi (anxious/depressed); 2) menarik diri/tertekan (withdrawn/ depressed); 3) keluhan fisik yang bukan disebabkan oleh sakit/penyakit (somatic complaints); 4) problem sosial/pergaulan (social problems); 5) kesulitan berpikir (thought problems); 6) kesulitan berkonsentrasi/memusatkan perhatian (attention problems); 7) perilaku melanggar norma/aturan (rule-breaking behavior); dan 8) perilaku agresif (aggressive behavior). Di Indonesia, terutama di Poliklinik Rumah Sakit Jiwa RSUP Dr. Cipto Mangunkusumo, Jakarta, diketahui bahwa problem emosi dan problem sosial yang menonjol pada anak dan remaja adalah kesulitan bergaul dengan teman sebaya (Wiguna, Manengkei, Pamela, Rheza, \& Hapsari, 2010).

Angold, Costello, \& Worthman (1998) melakukan riset mengenai depresi pada remaja usia 12-16 tahun dan mereka menemukan bahwa secara umum, tingkat depresi remaja perempuan lebih tinggi daripada remaja laki-laki. Depresi pada remaja perempuan mencapai puncaknya pada usia 13 tahun, kemudian menurun seiring dengan waktu dan stabil hingga usia 16 tahun. Namun pada remaja lakilaki, depresi mulai meningkat sejak usia 12 tahun dan memuncak di usia 16 tahun. Dengan demikian dapat disimpulkan bahwa ada perbedaan gender pada pola depresi remaja usia 12-16 tahun. Problem kecemasan (anxiety problems) umumnya memuncak di masa remaja, terutama pada remaja perempuan (Zahn-Waxler, Shirtcliff, \& Marceau, 2008). Lebih lanjut Zahn-Waxler dkk (2008) menjelaskan mengenai perbedaan gender pada problem emosi remaja, yakni karena remaja lakilaki dan perempuan: (1) memiliki faktor risiko dari lingkungan yang berbeda; (2) memiliki proses biologis atau mekanisme ekspresi gen yang berbeda; (3) mengalami interaksi antara faktor biologis dan lingkungan secara berbeda.

Anak maupun remaja dengan masalah emosi dan perilaku seringkali mengalami perlakuan yang tidak tepat dari lingkungannya, misalnya mendapatlan labeling atau stigma negatif. Bahkan guru di sekolah seringkali memiliki anggapan yang keliru dengan berpikir bahwa mereka adalah anak yang nakal dan sulit diatur, 
sulit dididik, trouble maker, sehingga bersikap kurang responsif bila prestasi akademik mereka menurun dari waktu ke waktu, dan jarang memberikan masukan atau intervensi yang signifikan. Teman sebaya pun seringkali memilih untuk menjauhi mereka sehingga kesempatan untuk belajar bersosialisasi menjadi berkurang, yang akhirnya berdampak pada makin rendahnya ketrampilan mereka dalam bergaul. Pada umumnya respon orangtua cenderung negatif sehingga tidak jarang interaksi antara orangtua dan anak menjadi makin renggang. Munculnya berbagai bentuk persoalan emosi dan perilaku pada remaja menunjukkan bahwa usia merupakan salah satu faktor risiko sehingga diperlukan upaya untuk melakukan deteksi dini dan indetifikasi problem emosi/perilaku anak sedini mungkin. Jika diabaikan atau tidak tertangani dengan baik, problem emosi dan problem pada remaja akan menjadi semakin buruk dan mengganggu (Harland, Rijneveld, Brugman, Verloove-Vanhrick, \& Verhulst, 2002).

Penelitian sebelumnya menemukan adanya problem emosi pada 236 responden yang terdiri dari anak, remaja, dan orang dewasa di propinsi Jawa Tengah (Ediati, Faradz, Juniarto, van der Ende, Drop, \& Dessens, 2015). Problem emosi yang ditemukan mencakup internalizing maupun externalizing problems. Namun dalam penelitian tersebut, hanya 48 remaja yang terlibat. Diperlukan penelitian lebih lanjut yang melibatkan lebih banyak responden untuk mengetahui prevalensi problem emosi pada remaja. Oleh karena itulah, diperlukan referensi berdasarkan kajian empiris mengenai profil problem emosi terutama pada remaja pelajar sekolah menengah (SMP-SMA). Penelitian ini bertujuan untuk mengidentifikasi profil problem emosi pada remaja pelajar SMP dan SMA di Kota Semarang, Jawa Tengah.

\section{METODE}

Penelitian ini bersifat cross-sectional yang dilakukan di wilayah Kota Semarang, Jawa Tengah. Subjek penelitian adalah 568 remaja pelajar SMP dan SMA yang berusia antara 13-17 tahun, berjenis kelamin lakilaki maupun perempuan, dan pada saat penelitian berlangsung berstatus sebagai siswa-siswi aktif di SMP atau SMA di Kota Semarang. Sebanyak empat sekolah berpartisipasi dalam penelitian ini. Subjek diperoleh dengan metode cluster sampling pada sekolah-sekolah tersebut. Siswa-siswi yang berpartisipasi dalam penelitian ini adalah siswa-siswi kelas VIII dan kelas X. Youth Self Report (YSR) edisi Bahasa Indonesia dalah instrumen yang digunakan untuk mengumpulkan data problem emosi remaja. YSR merupakan salah satu skala asesmen problem emosi yang telah distandardisasi dan didisain khusus untuk diisi langsung oleh remaja berusia 11-18 tahun (Achenbach \& Rescorla, 2001). YSR terdiri dari 119 aitem yang berasal dari delapan skala problem emosi, yakni: 1) Anxious/Depressed;

Withdrawn/Depressed; 3) Somatic complaints; 4) Social problems; 5) Thought problems; 6) Attention problems; 7) Rule-breaking behavior; dan 8) Aggressive behavior. Respon jawaban tiap aitem berupa tiga pilihan frekuensi terjadinya sindrom dalam enam bulan terakhir, yakni; 1) Tidak pernah (skor 0); 2) Kadang-kadang (skor 1); dan Sering/Selalu (skor 2). YSR telah divalidasi di 23 negara dan hasil uji reliabilitas dan validitas lintas budaya menunjukkan hasil yang memuaskan (Ivanova dkk, 2007). YSR versi Bahasa Indonesia telah diuji validitas dan reliabilitasnya dengan melibatkan 1154 siswa SMP/SMA di Jawa Tengah (Ediati, Faradz, Verrips, Juniarto, Drop, \& Dessens, 2014) dan hasilnya menunjukkan bahwa YSR edisi Bahasa Indonesia mengikuti model skala aslinya, yakni 
memiliki delapan skala dengan alpha Cronbach berkisar antara 0,62 (skala Social problem) hingga 0,92 (skala Total problem) sehingga dapat disimpulkan YSR memiliki kualitas psikometrik baik. Data yang diperoleh selanjutnya dianalisis dengan menggunakan teknik uji t (t-test) untuk menguji perbedaan diantara dua kelompok (sekolah atau jenis kelamin). Perhitungan statistik kerjakan dengan menggunakan software SPSS edisi 19.

\section{HASIL DAN PEMBAHASAN}

\section{Deskripsi Subjek}

Subjek dalam penelitian ini adalah 568 remaja dengan rerata usia 13,99 $\pm 1,108$ tahun yang mayoritas adalah remaja Sekolah Menengah Pertama (337/59,3\%) dan perempuan $(334 / 58,8 \%)$. Data selengkapnya dapat dilihat pada Tabel 1.

Tabel 1. Deskripsi subjek penelitian $(\mathbf{N}=$ 568)

\begin{tabular}{lcc}
\hline Aspek & SMP & SMA \\
\hline$n$ & 337 & 231 \\
& $(59,3 \%)$ & $(40,7 \%)$ \\
Jenis & &
\end{tabular}

Kelamin:

Laki-Laki

Perempuan

$169(50,1 \%) \quad 65(28,1 \%)$

$168(49,9 \%) \quad 166(71,9 \%)$

Usia $(M \pm 13,21 \pm \quad 15,14 \pm$

SD) tahun $\quad 0,616 \quad 0,545$

Keterangan: $\mathrm{M}=$ mean; $\mathrm{SD}=$ standard deviation; SMP = Sekolah Menengah Pertama; SMA = Sekolah Menengah Atas

Profil problem emosi remaja pelajar SMP dan SMA di Kota Semarang

Secara umum, siswa-siswi SMP dan SMA tampak memiliki profil problem emosi yang relatif sama, seperti yang ditunjukkan oleh Gambar 1. Problem emosi yang dominan pada siswa-siswi SMP dan SMA adalah; 1) perilaku agresif, 2) cemas/depresif, 3) kesulitan memusatkan perhatian/konsentrasi, dan 4) kesulitan dalam menjalin relasi dengan orang lain. Secara spesifik, remaja dalam penelitian ini mengaku suka membantah
(438/77,11\%), mengkhawatirkan banyak hal dalam kehidupannya (384/67,6\%), merasa tidak dicintai $(185 / 32,5 \%)$, merasa tidak berharga $(259 / 45,6 \%)$, cenderung memendam perasaan/merahasikan sesuatu (320/56,34\%), memilih menarik diri dari pergaulan $(167 / 29,4 \%)$, bahkan pernah berpikir untuk mengakhiri hidupnya $(62 / 10,9 \%)$. Kecemasan dan emosi depresif tampak lebih menonjol pada siswa-siswi SMA daripada siswa-siswi SMP sedangkan perilaku melanggar aturan (rule-breaking behavior) tampak lebih menonjol pada siswa-siswi SMP. Namun secara keseluruhan, remaja SMP memiliki lebih banyak problem emosi daripada remaja SMA $(t(566)=2,08 ; p=0,038)$, terutama dalam hal bergaul $(t(566)=2,92$; $p=0,004)$, berpikir $(t(566)=2,47 ; p=$ $0,014)$, keluhan somatik $(t(566)=2,98 ; p=$ $0,002)$, dan melanggar aturan $(t(566)=$ $6,63 ; p<0,001)$. Disamping itu, remaja SMP lebih sering mengalami externalizing problem daripada remaja SMA $(t(566)=$ $3,37 ; p=0,001)$.

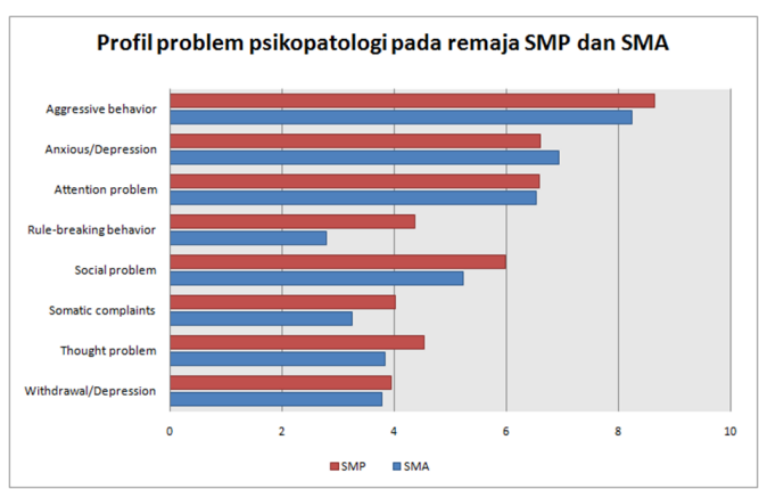

Gambar 1

Profil problem psikopatologi pada siswa-siswi SMP dan SMA di Kota Semarang

Gambar 2 menunjukkan frekuensi problem emosi secara umum di kelompok remaja SMP, dimana perempuan memiliki lebih banyak problem emosi daripada lakilaki $(t(335)=-3,56 ; p<0,001)$ sedangkan pada remaja SMA tidak terdapat perbedaan problem psikologis yang siginifikan antara 
laki-laki dan perempuan $(t(229)=0,19 ; p$ $=0,846$ ).

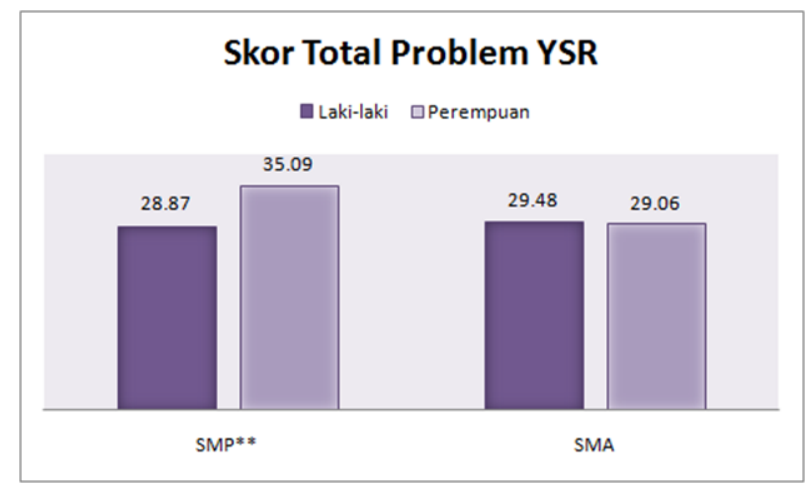

Gambar 2

Skor Total Problem (skala YSR) pada siswa-siswi SMP dan SMA

Jika dilihat secara lebih mendalam, yakni dalam hal internalizing ataupun externalizing behavior, maka tampak jelas ditunjukkan dalam Gambar 3 bahwa diantara remaj a SMP, perempuan lebih sering memiliki internalizing problem daripada laki-laki $(t(335)=-5,76 ; p<$ 0,001) sedangkan diantara remaja SMA, tidak terdapat perbedaan gender dalam hal internalizing problem $(t(229)=-1,11 ; p=$ 0,266).

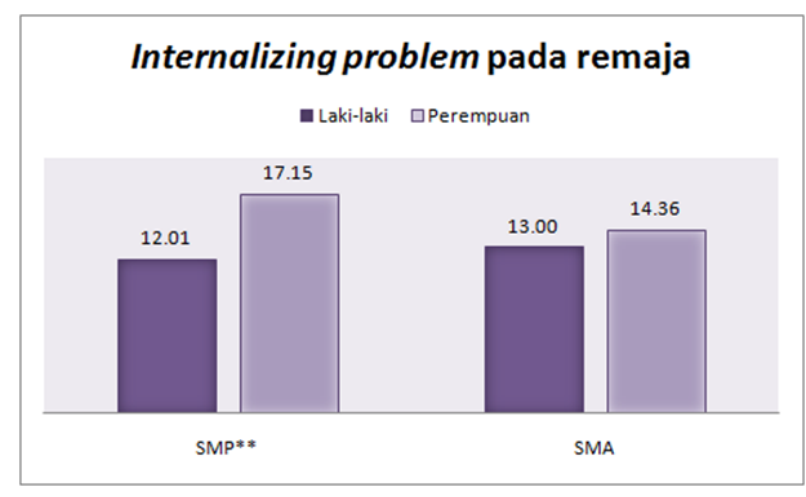

Gambar 3

Gambaran internalizing problem pada siswa-siswi SMP dan SMA
Dalam hal externalizing behavior (Gambar 4) di kalangan remaja SMP, tidak terdapat perbedaan yang signifikan antara remaja laki-laki dan perempuan $(t(335)=-0,46 ; p$ $=0,643$ ), namun di kalangan remaja SMA, externalizing behavior lebih banyak ditemukan pada laki-laki daripada perempuan $(t(229)=2,10 ; p=0,037)$.

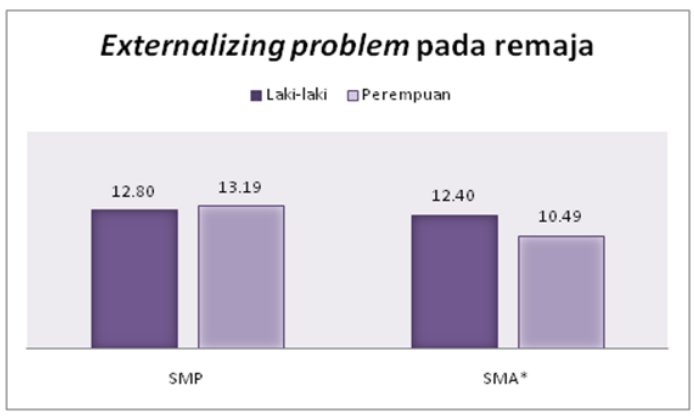

Gambar 4

Gambaran externalizing problem pada siswa-siswi SMP dan SMA

Perbedaan gender pada profil psikopatologi remaja SMP ditampilkan dalam Tabel 2. Sedangkan Tabel 3 menampilkan profil psikopatologi remaja SMA ditinjau dari gender.

Dari Tabel 2 dapat disimpulkan bahwa problem emosi pada remaja SMP lebih banyak ditemukan pada remaja perempuan daripada remaja laki-laki, terutama dalam hal kecemasan/depresif $(t(335)=-6,51 ; p<$ $0,001)$; menarik diri dari pergaulan $(t(335)$ $=-4,26 ; p<0,001)$; keluhan somatik $(t(335)=-2,86 ; p=0,004)$; kesulitan bergaul $(t(335)=-3,30 ; p=0,001)$; memusatkan konsentrasi $(t(335)=-2,39 ; p$ $=0,017)$, dan internalizing problem $(t(335)$ $=-5,76 ; p<0,001)$.

Tabel 3 menampilkan perbedaan gender pada profil problem emosi remaja SMA. Secara umum, laki-laki lebih sering mengalami externalizing problem $(t(229)=$ $2,10 ; p=0,037)$ dan lebih banyak melanggar aturan $(t(229)=4,44 ; p<$ $0,001)$ daripada perempuan. Sebaliknya, 
perempuan lebih sering mengalami keluhan fisik karena problem psikologis daripada laki-laki $(t(229)=-3,09 ; p=$ 0,001).

Penelitian ini bertujuan untuk melihat profil problem emosi pada remaja pelajar SMP dan SMA di Kota Semarang, Jawa Tengah. Problem emosi di kalangan remaja seolah dianggap wajar karena sudah sering diberitakan dan dilaporkan, namun hingga saat ini masih menjadi problem. Hasil penelitian ini menemukan lima kategori problem emosi yang dominan ditemukan pada remaja SMP dan SMA di Kota Semarang, yakni perilaku agresif, kecemasan/depresi, kesulitan konsentrasi, dan problem relasi interpersonal. Di samping itu, tampak ada perbedaan gender pada profil problem emosi remaja laki-laki dan perempuan. Remaja perempuan tampak lebih sering mengalami internalizing problem, seperti lebih sering merasa cemas/depresi, menarik diri dari pergaulan, memiliki keluhan fisik yang bukan disebabkan oleh sakit/penyakit (somatic complaints), sedangkan remaja laki-laki tampak sering mengalami externalizing problem, seperti lebih sering bertindak melanggar aturan (rule-breaking behavior).

Pada penelitian ini juga ditemukan bahwa problem psikologis tampak lebih banyak ditemukan pada remaja SMP daripada remaja SMA yang mengindikasikan adanya kesulitan remaja dalam menghadapi masa transisi

\section{Tabel 2}

Rerata (Mean) dan Standar Deviasi skor YSR pada siswa-siswi SMP

\begin{tabular}{llll}
\hline \multirow{2}{*}{ Problem (YSR) } & $\mathrm{M} \pm \mathrm{SD}$ & \\
\cline { 2 - 4 } & Laki-laki $(\mathrm{n}=169)$ & Perempuan $(\mathrm{n}=168)$ & $<.001^{* *}$ \\
\hline Total problem & $28.87 \pm 16.50$ & $35.09 \pm 15.66$ & $<.001^{* *}$ \\
Internalizing problem & $12.01 \pm 8.01$ & $17.15 \pm 8.39$ & .643 \\
Externalizing problem & $12.80 \pm 8.13$ & $13.19 \pm 7.11$ & $<.001^{* *}$ \\
Anxious/Depression & $5.17 \pm 3.76$ & $8.07 \pm 4.40$ & $<.001^{* *}$ \\
Withdrawal/Depression & $3.31 \pm 2.59$ & $4.58 \pm 2.86$ & $.004^{*}$ \\
Somatic complaints & $3.53 \pm 3.10$ & $4.51 \pm 3.19$ & $.001^{*}$ \\
Social problem & $5.43 \pm 3.10$ & $6.55 \pm 3.14$ & .056 \\
Thought problem & $4.17 \pm 3.45$ & $4.92 \pm 3.67$ & $.017^{*}$ \\
Attention problem & $6.20 \pm 2.93$ & $6.97 \pm 2.98$ & .133 \\
Rule-breaking behavior & $4.63 \pm 3.55$ & $4.08 \pm 3.21$ & $.079 *$ \\
Aggressive behavior & $8.17 \pm 5.22$ & $9.11 \pm 4.57$ & \\
\hline Keteran &
\end{tabular}

Keterangan: YSR = Youth Self Report $; \mathrm{M}=$ mean $; \mathrm{SD}=$ standard deviation $; * p<.05 ; * * p<.001$

\section{Tabel 3}

Rerata (Mean) dan Standar Deviasi skor YSR pada siswa-siswi SMA

\begin{tabular}{|c|c|c|c|}
\hline \multirow{2}{*}{ Problem (YSR) } & \multicolumn{2}{|l|}{$\mathrm{M} \pm \mathrm{SD}$} & \multirow[b]{2}{*}{$p$} \\
\hline & Laki-laki $(n=65)$ & Perempuan $(n=166)$ & \\
\hline Total problem & $29.48 \pm 15.04$ & $29.06 \pm 14.53$ & .846 \\
\hline Internalizing problem & $13.00 \pm 8.13$ & $14.36 \pm 8.38$ & .266 \\
\hline Externalizing problem & $12.40 \pm 6.87$ & $10.49 \pm 5.94$ & $.037 *$ \\
\hline Anxious/Depression & $6.54 \pm 4.31$ & $7.10 \pm 4.48$ & .385 \\
\hline Withdrawal/Depression & $4.09 \pm 2.98$ & $3.66 \pm 2.69$ & .285 \\
\hline Somatic complaints & $2.37 \pm 2.29$ & $3.60 \pm 2.91$ & $.001 *$ \\
\hline Social problem & $5.48 \pm 3.10$ & $5.14 \pm 2.74$ & .417 \\
\hline Thought problem & $4.00 \pm 3.23$ & $3.76 \pm 3.06$ & .597 \\
\hline Attention problem & $6.45 \pm 2.74$ & $6.57 \pm 3.26$ & .777 \\
\hline Rule-breaking behavior & $3.80 \pm 2.59$ & $2.39 \pm 1.99$ & $<.001 * *$ \\
\hline Aggressive behavior & $8.60 \pm 4.95$ & $8.10 \pm 4.43$ & .459 \\
\hline
\end{tabular}


memasuki tahapan perkembangan masa remaja. Model pembelajaran yang berbeda dengan SD, lingkungan baru, tuntutan peran baru (bukan kanak-kanak lagi) serta perubahan biologis, emosional, hormonal yang terjadi dalam waktu hampir bersamaan, mungkin menyulitkan bagi remaja dalam beradaptasi. Dalam kelompok remaja SMA, perbedaan gender pada problem emosi tidak ditemukan. Hal ini mengindikasikan bahwa problem emosi yang muncul pada remaja dalam penelitian ini tampaknya tidak tipikal gender, tetapi cenderung dipengaruhi oleh faktor usia. Seiring dengan bertambahnya usia dan kematangan pribadi remaja, tampaknya meningkat pula kemampuannya dalam melakukan penyesuaian diri terhadap tugas perkembangan dan perubahan-perubahan yang terjadi pada masa remaja.

Penelitian ini secara umum menemukan bahwa remaja perempuan dalam penelitian ini memiliki lebih banyak problem emosi daripada remaja laki-laki. Disamping itu ada beberapa domain problem emosi yang tampaknya tipikal perempuan, seperti depresi/cemas maupun keluhan somatik (keluhan fisik yang disebabkan oleh tekanan psikis). Hasil penelitian ini sejalan dengan temuan sebelumnya (Angold, Costello, Erkanli, \& Worthman, 1999; Collishaw et al., 2010) yang menemukan bahwa depresi pada remaja perempuan lebih tinggi daripada remaja laki-laki. Finkenauer, Engels, \& Baumeister (2005) berpendapat bahwa perbedaan gender dalam hal problem emosi pada remaja dapat terjadi dikarenakan penerapan pola asuh orangtua yang berbeda pada anak laki-laki dan perempuan, terutama dalam hal penggunaan kontrol perilaku. Adalah hal yang wajar bila externalizing problem ditemukan lebih banyak pada remaja lakilaki dan internalizing problem ditemukan lebih banyak pada remaja perempuan karena hal ini adalah perbedaan ekspresi emosi semata (Finkenauer, Engels, \&
Baumeister, 2005). Hal ini mengindikasikan perlu perhatian khusus kepada remaja perempuan untuk mendapatkan edukasi dan intervensi untuk meningkatkan kualitas kesehatan mental remaja.

Penelitian ini juga menemukan mayoritas subjek $(77,11 \%)$ mengaku suka membantah. Hal ini memang merupakan salah satu karakteristik remaja pada umumnya namun juga menunjukkan bahwa $23 \%$ masih menganut nilai-nilai yang ditanamkan orangtua dalam keluarganya sehingga tidak mudah bertengkar atau membantah orang lain. Hal lain yang cukup memprihatinkan bahwa banyaknya remaja di kota besar Semarang yang merasa cemas/khawatir dengan kehidupannya $(67,6 \%)$, merasa tidak dicintai $(32,5 \%)$, merasa tidak berharga $(45,6 \%)$, dan tampak mengalami kesulitan menyelesaikan persoalannya sendiri sehingga cenderung menutup diri $(56,34 \%)$, memilih menarik diri dari pergaulan $(29,4 \%)$, bahkan berpikir untuk bunuh diri $(10,9 \%)$. Tingginya angka bunuh diri pada remaja pelajar juga ditemukan dalam penelitian sebelumnya di Korea (Kim, Koh, \& Leventhal, 2005).

Masa remaja merupakan periode yang membutuhkan perhatian banyak pihak, terutama orangtua dan pihak sekolah karena banyaknya problem emosi yang dihadapi remaja. Problem emosi dan problem perilaku pada siswa-siswi sekolah pada umumnya ditangani secara individual melalui program bimbingan dan konseling di sekolah. Namun melihat banyaknya remaja yang melaporkan problem emosinya dalam penelitian ini mengindikasikan perlu dirancang suatu model program penanganan dan pencegahan yang berbasis sekolah dan yang memungkinkan untuk dilakukan secara klasikal (Briesch, Hagermoser Sanetti, \& Briesch, 2010). Diperlukan 
kesadaran semua pihak (orangtua, sekolah, dan komunitas psikologi) untuk menyusun model intervensi psikologis yang bersifat preventif maupun kuratif, yang sensitif terhadap perbedaan gender, yang didisain khusus berbasis sekolah.

\section{KESIMPULAN}

Secara umum, remaja SMP memiliki lebih banyak problem emosi daripada remaja SMA, terutama dalam hal bergaul, berpikir, keluhan somatik, dan melanggar aturan. Disamping itu, remaja SMP lebih sering mengalami externalizing problem daripada remaja SMA. Perbedaan gender tampak mempengaruhi profil problem problem emosi pada remaja pelajar SMPSMA. Pada kelompok pelajar SMP, perempuan memiliki lebih banyak problem emosi daripada laki-laki, terutama dalam hal kecemasan/depresi, menarik diri dari pergaulan, keluhan somatik, kesulitan bergaul, memusatkan konsentrasi, dan internalizing problem. Sedangkan pada kelompok pelajar SMA, laki-laki lebih sering mengalami externalizing problem dan lebih banyak melanggar aturan daripada perempuan. Sebaliknya, perempuan lebih sering mengalami keluhan fisik karena problem psikologis daripada laki-laki. Program intervensi preventif maupun kuratif terhadap problem emosi pada remaja pelajar SMP-SMA perlu dirancang dengan memperhatikan tipe problem emosi yang khas pada usia dan jenis kelamin tertentu serta menggunakan pendekatan berbasis sekolah sehingga bisa menjangkau remaja yang membutuhkan secara luas.

\section{DAFTAR PUSTAKA}

Achenbach, T. M., \& Rescorla, L. A. (2001). Manual for the ASEBA School-age forms and profiles. Burlington, VT: University of Vermont, Research Center for Children, Youth, and Families.
Angold, A., Costello, E. J., Erkanli, A., \& Worthman, C. M. (1999). Pubertal changes in hormone levels and depression in girls. Psychological Medicine, 29(5), 1043-53.

Angold, A, Costello, E. J., \& Worthman, C. M. (1998). Puberty and depression: the roles of age, pubertal status and pubertal timing. Psychological Medicine, 28(1), 5161.

Beesdo, K., Bittner, A., Pine, D. S., Stein, M. B., Hofler, M., Lieb, R., Wittchen, H. U. (2007). Incidence of social anxiety disorder and the consistent risk for secondary depression in the first three decades of life. Archives of General Psychiatry, 64:903-912.

Briesch, A. M., Hagermoser Sanetti, L. M., \& Briesch, J. M. (2010). Reducing the Prevalence of Anxiety in Children and Adolescents: An Evaluation of the Evidence Base for the FRIENDS for Life Program. School Mental Health. http://doi.org/10.1007/s12310-0109042-5

Collishaw, S., Maughan, B., Natarajan, L., \& Pickles, A. (2010). Trends in adolescent emotional problems in England: A comparison of two national cohorts twenty years apart. Journal of Child Psychology and Psychiatry, 51(8), 885-894

Donovan , C. L., \& Spence, S. H. (2000). Prevention of childhood anxiety disorders. Clinical Psychological Review, 20:509-531.

Ediati, A., Faradz, S. M. H., Verrips, G. H. W., Juniarto, A. Z., Drop, S. L. S., \& Dessens, A. B. (2014). Healthrelated quality of life in Indonesian children, adolescents, and adults with disorders of sex development. Dalam 
Ediati, A. (2014). Disorders of sex development in Indonesia: The course of psychological development in late identified patients. Rotterdam: Erasmus University Rotterdam.

Ediati, A., Faradz, S. M. H., Juniarto, A. Z., van der Ende, J., Drop, S. L. S., \& Dessens, A. B. (2015). Emotional and behavioral problems in lateidentified Indonesian patients with disorders of sex development. Journal of Psychosomatic Research, 79(1), 76-84.

Finkenauer, C., Engels, R. C. M. E., \& Baumeister, R. F. (2005). Parenting behavior and adolescent behavioral and emotional problems: The role of self- control. International Journal of Behavioral Development, 29(1), 5869.

Harland, P., Reijneveld, S. A., Brugman, E., Verloove-Vanhorick, S. P., \& Verhulst, F. C. (2002). Family factors and life events as risk factors for behavioural and emotional problems in children. European Journal of Child and Adolescent Psychiatry, 11:176-184.

Ivanova, M. Y., Achenbach, T. M., Rescorla, L. a, Dumenci, L., Almqvist, F., Bilenberg, N., ...
Verhulst, F. C. (2007). The generalizability of the Youth SelfReport syndrome structure in 23 societies. Journal of Consulting and Clinical Psychology, 75(5), 729-38.

Kim, Y. S., Koh, Y.-J., \& Leventhal, B. (2005). School bullying and suicidal risk in Korean middle school students. Pediatrics, 115(2), 357-63.

Sourander, A., \& Helstelä, L. (2005). Childhood predictors of externalizing and internalizing problems in adolescence. A prospective followup study from age 8 to 16. European Child \& Adolescent Psychiatry, 14(8), 415-23.

Wiguna, T., Manengkei, P.S.K., Pamela, C., Rheza, A.M., \& Hapsari, W.A. (2010). Masalah Emosi dan Perilaku pada Anak dan Remaja di Poliklinik Jiwa Anak dan Remaja RSUPN dr. Ciptomangunkusumo (RSCM), Jakarta. Sari Pediatri, 12 (4): 270-7.

Zahn-Waxler, C., Shirtcliff, E. a, \& Marceau, K. (2008). Disorders of childhood and adolescence: gender and psychopathology. Annual Review of Clinical Psychology, 4, 275-303. 